\title{
Cardiac progenitor cell-derived exosomes promote H9C2 cell growth via Akt/mTOR activation
}

\author{
SHENTANG LI ${ }^{1}$, JIE JIANG ${ }^{1}$, ZUOCHENG YANG $^{1}$, ZHUOYING LI $^{1}$, XING MA ${ }^{2}$ and XIN LI \\ ${ }^{1}$ Department of Pediatrics, The Third Xiangya Hospital, Central South University, Changsha, Hunan 410013; \\ ${ }^{2}$ State Key Laboratory of Advanced Welding and Joining, Harbin Institute of Technology (Shenzhen), \\ Shenzhen, Guangdong 518055, P.R. China
}

Received December 5, 2017; Accepted May 18, 2018

DOI: 10.3892/ijmm.2018.3699

\begin{abstract}
Exosomes are cell-derived vesicles released from a variety of mammalian cells that are involved in cell-to-cell signalling. It has been reported that cardiac progenitor cells (CPCs) derived from an adult heart are one of the most promising stem cell types for cardioprotection and repair. The mammalian target of rapamycin (mTOR) signalling pathway is a pivotal regulator in CPCs, therefore, CPC-derived exosomes were used in the present study to investigate whether it can promote $\mathrm{H} 9 \mathrm{C} 2$ cell growth through the protein kinase $\mathrm{B}$ (PKB, or Akt)/mTOR signalling pathway. The CPCs were isolated from Sprague-Dawley hearts. Following treatment with a specific medium, the exosomes were purified and identified by electron micrograph and western blot assays, using CD63 and CD81 as markers. The methyl-thiazolyl-tetrazolium and 5-ethynyl-2'-deoxyuridine methods were used to detect H9C2 cell growth. The expression of Akt and mTOR were detected by western blot analysis following treatment with 200 or $400 \mu \mathrm{g} / \mathrm{ml}$ of exosomes for 24 or $48 \mathrm{~h}$, respectively. It was found that, compared with higher concentrations of exosomes, prolonging the duration of exposure promoted cell growth. Accordingly, CPC-derived exosomes stimulated the expression of Akt to a marked degree; groups treated with exosomes for $48 \mathrm{~h}$ showed higher expression of Akt than those treated for $24 \mathrm{~h}$ at the same concentration. mTOR was also stimulated by CPC-derived exosomes. The activation of mTOR increased in accordance with the treatment time at an exosome concentration of $200 \mu \mathrm{g} / \mathrm{ml}$ and decreased with treatment time at an exosome concentration of $400 \mu \mathrm{g} / \mathrm{ml}$. In conclusion, the present study demonstrated that CPC-derived exosomes promoted $\mathrm{H} 9 \mathrm{C} 2$ cell growth via the activation of $\mathrm{Akt} / \mathrm{mTOR}$ in a time-dependent manner at a relatively low
\end{abstract}

Correspondence to: Dr Xin Li, Department of Pediatrics, The Third Xiangya Hospital, Central South University, 138 Tongzipo Road, Changsha, Hunan 410013, P.R. China

E-mail: lixinwin_2008@hotmail.com

Key words: cardiac progenitor cells, exosomes, Akt, mammalian target of rapamycin, cell growth exosome concentration, which may provide a novel therapy for cardiovascular disease.

\section{Introduction}

Cardiovascular disease is one of the most significant contributors to morbidity and mortality rates in children around the world. Damaged cardiac tissue is unable to repair itself following injury, warranting the development of alternative therapies. An increasing number of studies have found that exosomes, a group of membrane vesicles with a certain volume that are naturally derived from mammalian cells, may be essential in cardiac cell communication and repair $(1,2)$, although their precise cellular origin and mechanism of action remain to be fully elucidated.

Exosomes, which range between 30 and $100 \mathrm{~nm}$ in size, are a type of extracellular vesicle; ultracentrifugation on a linear sucrose gradient (2-0.25 $\mathrm{M}$ sucrose) revealed that they have a density ranging between 1.13 and $1.19 \mathrm{~g} / \mathrm{ml}(3,4)$. They are set apart from other extracellular vesicles, including apoptotic bodies and microvesicles, owing to their unique qualities (5). Exosomes can transfer molecules from one cell to another via membrane vesicle trafficking and can perform the vital function of cell-to-cell communication in physiological and pathophysiological conditions (6,7). Exosomes have potential applications as novel bio-carriers for gene and drug delivery (8), which depend on their inner materials, including proteins, microRNAs (miRNAs) and cytokines, and their cell types.

Wu et al reported that gastric cancer-derived exosomes can promote tumour cell proliferation by stimulating the nuclear factor- $\kappa \mathrm{B}$ pathway (9). Another study found that fibroblasts exhibited uptake of exosomes derived from human amniotic epithelial cells (hAECs-Exo), and the migration and proliferation functions of these exosomes were promoted by hAECs-Exo via the activation of matrix metalloproteinase-1 (10). These studies focused on different exosomes, however, a number of discussed the roles of CPC-derived exosomes and their mechanisms. CPCs derived from adult hearts have gradually emerged as one of the most promising stem cell types for cardioprotection and repair through inducing differentiation and paracrine effects (11). Therefore, CPC-derived exosomes are involved in treating cardiovascular diseases, including 
protecting the ischemic myocardium from acute ischemia or reperfusion injury (11), inhibiting cardiomyocyte (CM) apoptosis and improving cardiac function following myocardial infarction (2). However, further investigations are required to better understand the underlying mechanisms.

The Akt/mammalian target of rapamycin (mTOR) signalling pathway is an important regulator in cell differentiation, growth and apoptosis, angiogenesis, and protein synthesis and degradation. Akt is a serine/threonine-specific protein kinase that is involved in multiple cellular processes, including glucose metabolism, apoptosis, cell proliferation, transcription and cell migration, through different downstream factors. The Akt kinase family contains three members with a broadly similar structure: Akt1, Akt2 and Akt3. All three consist of a conserved N-terminal pleckstrin homology domain, a central catalytic domain and a $\mathrm{C}$-terminal regulatory hydrophobic motif. Although they have similar mechanisms of exhibiting regulation function, they possess unique features (12). Akt1 and Akt 2 are widely expressed in various mammalian cells, whereas Akt3 exhibits a tissue-specific expression. An early study demonstrated that cancer-derived exosomes promote tumour cell proliferation via the activation of Akt (13). mTOR, an important regulator of the cell cycle and protein synthesis, is a critical component in several signalling pathways, including phosphoinositide 3-kinase (PI3K)/Akt. mTOR regulates cell growth by accepting exogenous growth factors and insulin stimulation, which affects factors including the feeling of changes in energy and nutritional status. The present study focused on the roles of CPC-derived exosomes in rat heart cell growth, and the communication between CPC-derived exosomes and the Akt/mTOR signalling pathway during this growth.

\section{Materials and methods}

Animals. All experiments were conducted in accordance with the IRB of The Third Xiangya Hospital, Central South University (Changsha, China; No. 2015-S001). The study was performed on 15 8-week-old male Sprague-Dawley (SD) rats purchased from Hunan Silaike Jingda Experimental Animal Co., Ltd. (Changsha, China). The rats, having a body weight of $200 \pm 10 \mathrm{~g}$, were fed on a standard diet with tap water and maintained in environmentally controlled rooms at $22 \pm 2^{\circ} \mathrm{C}$ under a relative humidity of $50 \pm 10 \%$ with a $12 / 12 \mathrm{~h}$ light-dark cycle.

Isolated CPCs. The isolated adult CMs were prepared from the hearts of 2-month-old male SD rats. First, the rat heart tissue was aseptically isolated on a clean bench, washed with sterile phosphate-buffered saline (PBS) containing Heparin several times and then placed in a Petri dish. The tissue was sliced with scissors and a scalpel as finely as possible, and the tissue debris was loaded into a $15-\mathrm{ml}$ tube. Subsequently, $5 \mathrm{ml}$ of type IV collagenase digestion $(1 \mathrm{mg} / \mathrm{ml}$, containing DNase I) was added and digested for $5 \mathrm{~min}$ at $37^{\circ} \mathrm{C}$, three times in total. Following standing for $5 \mathrm{~min}$ at $4^{\circ} \mathrm{C}$ or being briefly centrifuged for $3 \mathrm{~min}$ at $4^{\circ} \mathrm{C}(980 \mathrm{x} \mathrm{g})$, the supernatant was discarded. The tissue block was cleaned with PBS three times, resuspended in CEM (IMDM containing 20\% FBS, $1 \%$ penicillin-streptomycin, $2 \mathrm{mM}$ L-glutamine, $0.1 \mathrm{mM}$ 2-hydroxy-1-ethanethiol) and inoculated in a $20-\mu \mathrm{g} / \mathrm{ml} \mathrm{FN-coated} \mathrm{petri} \mathrm{dish;} \mathrm{the} \mathrm{medium} \mathrm{was}$ replaced once every 2-3 days. Following 14 days of incubation, the dishes were gently washed three times with PBS and then digested for $1-2$ min with a $0.05 \%$ trypsin solution preheated to $37^{\circ} \mathrm{C}$; the cells were then collected. Finally, the cells were transferred to the culture bottle, and the medium was replaced once every 2-3 days.

Exosome isolation. CPC-exosome isolation was performed using ExoQuick-TC ${ }^{\mathrm{TM}}$ Exosome Isolation reagent (System Biosciences, Palo Alto, CA, USA), following the procedure outlined by the manufacturer. To prepare the exosome media prior to ExoQuick treatment, the concentration was increased from 50 to $130 \mu \mathrm{l}$ using an Amicon Ultra filter (EMD Millipore, Billerica, MA, USA) with a 100,000-molecular weight cutoff (14).

Exosome labelling with $\operatorname{DioC}_{18}(3)$ (DiO). The purified CPC-derived exosomes were labelled with a $\mathrm{DiO}$ green fluorescent labelling kit (Yeasen Company, Shanghai, China) in accordance with the manufacturer's protocol. The DiO concentration for exosome labelling was $0.5 \mu \mathrm{M} / \mu 1$ of exosomes from $1 \times 10^{4}$ cells. The labelled exosomes were stained with $\mathrm{DiO}$ dye in $100 \mu \mathrm{l}$ of dimethyl sulfoxide (DMSO) diluted with $100 \mu \mathrm{l}$ of Dulbecco's modified Eagle's medium (DMEM; Hyclone; GE Healthcare Life Sciences, Logan, UT, USA) for $20 \mathrm{~min}$ at $37^{\circ} \mathrm{C}$, and an equal volume of serum without exosomes was added to terminate the labelling. H9C2 cardiomyocytes are a clonal heart muscle cell line derived from embryonic rat hearts, which can retain several cardiomyocyte phenotypes. In the present study, the H9C2 cells were obtained from the Cell Bank of the Type Culture Collection of the Chinese Academy of Sciences (Shanghai, China) and incubated with the labelled CPC-exosomes for $12 \mathrm{~h}$ at $37^{\circ} \mathrm{C}$ and washed with PBS. The uptake of labelled exosomes by the H9C2 cells was detected using a fluorescence microscope (Olympus Corporation, Tokyo, Japan).

Transmission electron microscopy(TEM). The ultrastructure of exosomes was observed using TEM, according to the methods described in a previous study (15). Briefly, a resuspended pellet $(3 \mathrm{ml})$ of exosomes was fixed with $2.5 \%$ glutaraldehyde, post-fixed in buffered $1 \%$ osmium tetroxide with $1.5 \%$ potassium ferrocyanide, embedded in $1 \%$ agar and processed according to the standard EPON812 embedding procedure. The exosomes were visualised in thin $(60-\mathrm{nm})$ sections using TEM (FEI Company, Eindhoven, The Netherlands) at $80 \mathrm{kV}$.

Methyl-thiazolyl-tetrazolium (MTT) assay. The H9C2 cells were seeded at $1 \times 10^{4}$ cells/well in 96-well plates and treated with CPC-derived exosomes at 0, 50, 100, 200 and $400 \mu \mathrm{g} / \mathrm{ml}$, respectively. The cells were grown at $37^{\circ} \mathrm{C}$ in a humidified incubator with $5 \%$ carbon dioxide $\left(\mathrm{CO}_{2}\right)$ for 12,24 and $48 \mathrm{~h}$. The medium was then replaced with serum-free DMEM, and $20 \mu \mathrm{l}$ of MTT solution was added. Following further growth at $37^{\circ} \mathrm{C}$ in a humidified incubator with $5 \% \mathrm{CO}_{2}$ for $4 \mathrm{~h}$, the supernatant was carefully discarded, following which $150 \mu \mathrm{l}$ of DMSO was added to each well. Following vibrating for $10 \mathrm{~min}$, the optical density of each well was measured on an enzyme-linked immunosorbent detector at a wavelength of $560 \mathrm{~nm}$. 
5-Ethynyl-2'-deoxyuridine (EdU) assay. The H9C2 cells were seeded in 96-well plates at $1 \times 10^{4}$ cells per well and cultured to the normal growth stage. Subsequently, the cells were treated with CPC-derived exosomes for 24 and $48 \mathrm{~h}$ with final concentrations of 0,200 and $400 \mu \mathrm{g} / \mathrm{ml}$. The EdU solution (reagent A) was diluted with 1:1,000 cell medium to prepare the appropriate concentration of EdU medium (50 $\mu \mathrm{M})$. EDU medium $(100 \mu \mathrm{l})$ was added to each well, and the medium was discarded following $2 \mathrm{~h}$ of incubation. Subsequently, $50 \mu \mathrm{l}$ of fixative solution (4\% paraformaldehyde) was added to each well and incubated at room temperature for $30 \mathrm{~min}$. Following washing with PBS for $5 \mathrm{~min}, 100 \mu \mathrm{l}$ of penetrant was added to each well, incubated for 10 min with a decolourisation shaker and then washed once with PBS for 5 min. Following this, $100 \mu \mathrm{l}$ of $1 \mathrm{X}$ Apollo was added to each well and incubated with a decolourisation shaker in the dark at room temperature for $30 \mathrm{~min}$. Following incubation, $100 \mu \mathrm{l}$ of penetrant and $100 \mu \mathrm{l}$ of methanol were added to each well and washed. Reagent $\mathrm{F}$ was diluted with deionised water at a ratio of 1:100 to prepare an appropriate concentration of $1 \mathrm{X}$ Hoechst 33342 reaction solution, of which $100 \mu \mathrm{l}$ was added to each well and incubated for $30 \mathrm{~min}$; subsequently, the reactant was washed. The cells were observed immediately following staining under an Olympus microscope (Olympus Corporation) equipped with a Metamorph ${ }^{\circledR}$ image acquisition system (DP2-BSW software; version 2.1 Olympus Corporation).

Reverse transcription-quantitative polymerase chain reaction (RT-qPCR) analysis. The H9C2 cells in different groups were collected at each scheduled time point, and mRNA were extracted using an RNA extraction kit (Omega Bio-Tek, Inc., Norcross, GA, USA). The mRNA was reverse transcribed into cDNA following the RevertAid ${ }^{\mathrm{TM}}$ First Strand cDNA Synthesis kit (Thermo Fisher Scientific, Inc., Waltham, MA, USA). The real-time fluorescence RT-qPCR analysis was accomplished using a SYBR Green PCR Master mix kit (Applied Biosystems; Thermo Fisher Scientific, Inc.) containing $2 \mu \mathrm{l}$ cDNA and $0.5 \mu \mathrm{l}$ each primer $(10 \mu \mathrm{M})$, according to the manufacturer's protocol, with the following thermal cycling conditions for 40 cycles in total: $10 \mathrm{~min}$ at $95^{\circ} \mathrm{C}, 15 \mathrm{sec}$ at $95^{\circ} \mathrm{C}$ and $30 \mathrm{sec}$ at $60^{\circ} \mathrm{C}$. The primer sequences are listed in Table I. The signal of a gene was standardised with $\beta$-actin using the following formulas: $\Delta \mathrm{Cq}=\mathrm{Cq}$ target-Cq reference; and $\Delta \Delta \mathrm{Cq}=$ mean value of $\Delta \mathrm{Cq}$ control $-\Delta \mathrm{Cq}$ sample. Finally, the $2^{-\Delta \Delta \mathrm{Cq}}$ method (16) was used to calculate the differences in mRNA transcription levels.

Western blot analysis. The CPC-derived exosome samples, rat lymphocytes and $\mathrm{H} 9 \mathrm{C} 2$ cells from different groups were harvested and maintained on ice for 10 min following being washed twice with ice-cold PBS. Lysis buffer (80- $\mu$ l; Beyotime Institute of Biotechnology, Haimen China) containing $0.1 \%$ phenylmethylsulfonyl (CWBio, China) was added to each well. The cell lysates were collected using a scraper and centrifuged at $13,780 \mathrm{x}$ g for $15 \mathrm{~min}\left(4^{\circ} \mathrm{C}\right)$, and the supernatant was obtained. The protein concentration was detected using an enhanced BCA protein assay kit (Beyotime Institute of Biotechnology). Subsequently, $30 \mu \mathrm{g}$ of extracted protein was fractionated on $10-12 \%$ sodium dodecyl sulphatepolyacrylamide gels, electrophoretically transferred onto $0.45-\mu \mathrm{mPVDF}$ membranes
Table I. Primer sequences used for reverse transcription-quantitative polymerase chain reaction analysis.

\begin{tabular}{ll} 
Gene & \multicolumn{1}{c}{ Primer sequence $^{\prime}$} \\
\hline Rat-mTOR & F: 5' CCTCGGCACATCACTCCCTT 3' \\
& R: 5' GCTCCTACATTTCAGCACCCACT 3' \\
\multirow{2}{*}{ Rat-Akt1 } & F: 5' TACCTGAAGCTACTGGGCAAGGG 3' \\
& R: 5' CGGTCGTGGGTCTGGAATGAG 3' \\
Rat-Akt2 & F: 5' GATGGTAGCCAACAGTCTGAAGCA 3' \\
& R: 5' CCCTTGCCGAGGAGTTTGAGATA 3' \\
3-actin & F: 5' AAGATCAAGATCATTGCTCCTCC 3' \\
& R: 5' TAACAGTCCGCCTAGAAGCA 3'
\end{tabular}

mTOR, mammalian target of rapamycin; F, forward; R, reverse.

(EMD Millipore), and blocked with PBS containing $0.5 \%$ Triton-100 (CWBio) and 5\% non-fat dry milk for $1 \mathrm{~h}$. The membrane was then incubated with a specific primary antibody at $4^{\circ} \mathrm{C}$ overnight, as follows: Monoclonal anti-CD63 (1:500; cat no. ab108950; Abcam, Cambridge, MA, USA), monoclonal anti-CD-81 (1:200; cat no. sc-9158; Santa Cruz Biotechnology, Inc., Dallas, TX, USA), monoclonal anti-Akt antibody (1:1,000; cat no. \#9272; Cell Signaling Technology, Inc., Danvers, MA, USA), monoclonal anti-phosphorylated (p-)Akt antibody (1:2,000; cat no. \#4060; Cell Signaling Technology, Inc.), monoclonal anti-mTOR antibody (1:1,000; cat no. \#2983; Cell Signaling Technology, Inc.), monoclonal anti-p-mTOR antibody (1:1,000; cat no. \#5536; Cell Signaling Technology, Inc.) and monoclonal anti- $\beta$-actin antibody (1:4,000; cat no. 60008-1; ProteinTech Group, Inc., Chicago, IL, USA). This step was followed by incubation with horseradish peroxidase-conjugated secondary antibodies (1:6,000; goat anti-rabbit; cat no. SA00001-2; ProteinTech Group, Inc.) for $1 \mathrm{~h}$ at room temperature. Ultimately, the protein expression level was determined by enhanced chemiluminescence (Pierce; Thermo Fisher Scientific, Inc.) and analyzed using Quantity One software (version 4.6.2; Bio-Rad Laboratories, Inc., Hercules, CA, USA).

Statistical analysis. Two-way analysis of variance was performed with multiple comparisons and paired Student's t-tests with the statistical software SPSS v22.0 (IBM Corp., Armonk, NY, USA). Data are presented as the mean \pm standard error of the mean. $\mathrm{P}<0.05$ was considered to indicate a statistically significant difference.

\section{Results}

Identification of $\mathrm{CPC}$-derived exosomes. To extract the exosomes, the CPCs were first isolated from the SD rat heart tissue (Fig. 1A). When the exosomes had been prepared and purified using the ExoQuick-TC ${ }^{\mathrm{TM}}$ method, they were observed by TEM, and the markers were characterised by western blot analysis. As shown in previous studies, the exosomes were, $\sim 35.61 \pm 3.89 \mathrm{~nm}$ in diameter (Fig. 1B). Comparing the CPC-derived exosomes with the lymphocyte lysates, which 
A

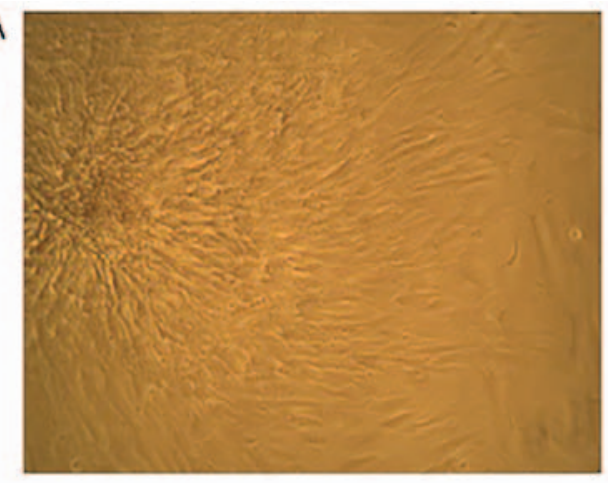

B

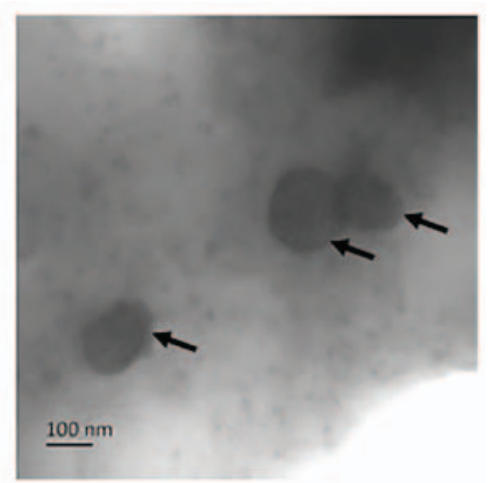

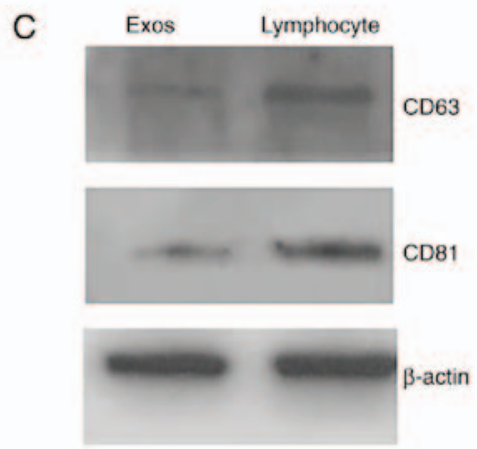

Figure 1. Identification of CPC-derived exosomes. (A) CPCs were isolated from Sprague-Dawley rat heart tissue (magnification, x200). (B) Exosomes were prepared and purified using the ExoQuick-TC ${ }^{\mathrm{TM}}$ method, and observed using transmission electron microscopy, showing small vesicles of $35.61 \pm 3.89$ nm in diameter. Scale bar $=100 \mathrm{~nm}$. The arrows indicate exosomes. (C) Marker proteins CD63 and CD81 of exosomes were examined via western blot analysis, using rats lymphocyte lysate as a control. CPCs, cardiac progenitor cells; Exos, exosomes.

have been shown to contain a large number of exosomes, revealed that the tetraspanin molecules CD63 and CD81 were abundant in the former (Fig. 1C).

Exosome labelling and uptake of exosomes by H9C2 cells. To determine whether CPC-derived exosomes were taken up by H9C2 cells, the exosomes were labelled with $\mathrm{DiO}$, a fluorescent cell linker compound that is incorporated into the cell membrane by selective partitioning. Following incubation of the $\mathrm{H} 9 \mathrm{C} 2$ cells with the exosomes labelled with $\mathrm{DiO}$, green fluorescence was observed in the cytoplasm of almost every H9C2 cell (Fig. 2), indicating that significant quantities of CPC-derived exosomes had been taken up by the H9C2 cells.

CPC-derived exosomes promote $\mathrm{H} 9 \mathrm{C} 2$ cell growth in a timeand concentration-dependent manner. Exosomes are now considered to be an important catalyst in cell proliferation and tissue repair. To investigate the effect of CPC-derived exosomes on $\mathrm{CMs}$, the present study determined $\mathrm{H} 9 \mathrm{C} 2$ cell growth via MTT and EdU assays with different exosome concentrations and treatment durations. It was found that the CPC-derived exosomes promoted $\mathrm{H} 9 \mathrm{C} 2$ cell growth. In addition, at a relatively low concentration, the higher the concentration, the more marked the stimulation effect under the same treatment time. In turn, the longer the treatment time, the more marked the stimulation effect at the same concentration (Fig. 3A-D).

CPC-derived exosomes stimulate the expression and phosphorylation of Akt. The PI3K/Akt/mTOR signalling pathway is important for cell proliferation. However, due to its frequent dysregulation, Akt is typically accepted as a promising anticancer therapeutic target (17). This signalling pathway is activated by various extracellular growth factors, including epidermal growth factor, insulin-like growth factor 1 and insulin, and simulates downstream mTOR signalling (18). To investigate whether it can be activated by CPC-derived exosomes in $\mathrm{CMs}$, the $\mathrm{H} 9 \mathrm{C} 2$ cells were treated with 200 and $400 \mu \mathrm{g} / \mathrm{ml}$ of exosomes for 24 and $48 \mathrm{~h}$, respectively. Following this, the mRNA and protein expression levels of Akt were analysed by RT-qPCR and western blot analyses. In these experiments, it was found that the mRNA and protein expression levels of Akt were increased; furthermore, the phosphorylation was increased in the two groups, and stimulation in the groups treated with 200 and $400 \mu \mathrm{g} / \mathrm{ml}$ of exosomes for $48 \mathrm{~h}$ was more marked than that in the groups treated with the same exosome concentrations for $24 \mathrm{~h}$. Compared with the groups treated with $200 \mu \mathrm{g} / \mathrm{ml}$ of exosomes, the activation in the $400 \mu \mathrm{g} / \mathrm{ml}$ group was higher at $24 \mathrm{~h}$ (Fig. 4A-D).

CPC-derived exosomes stimulate the expression and phosphorylation of $m T O R$ at a relatively low exosome concentration. mTOR has been reported to regulate homeostasis by directly influencing gene transcription, protein and lipid synthesis, and organelle biogenesis and maintenance in response to multiple extra- and intracellular signals, including growth factors and nutrients. This serine/threonine kinase has long been known as a critical regulator of cell proliferation. In the present study, the expression of mTOR was determined by RT-qPCR and western blot analyses, using H9C2 cells treated with 200 and $400 \mu \mathrm{g} / \mathrm{ml}$ of exosomes for 24 and $48 \mathrm{~h}$, respectively. Following exosome treatment, the mRNA expression of mTOR was stimulated, and the stimulation increased 

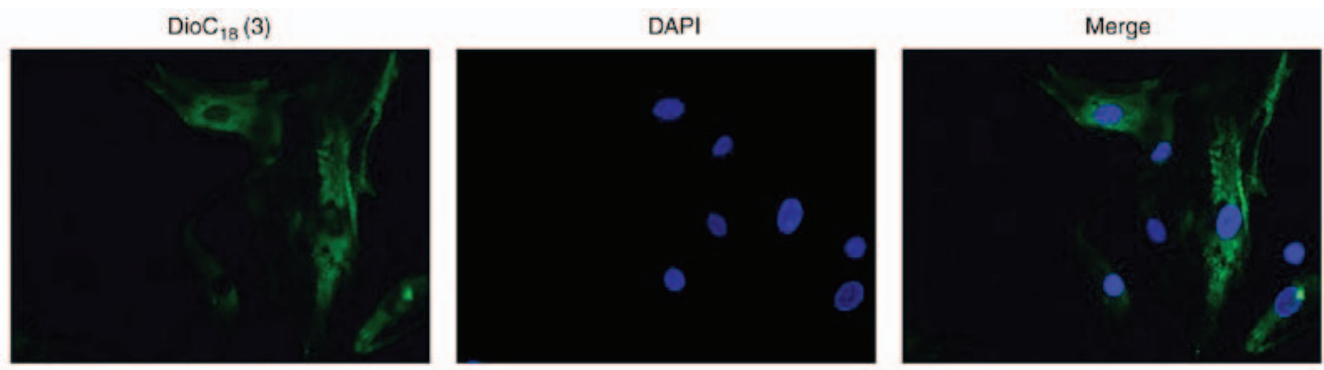

Figure 2. Exosome labeling and uptake of exosomes by $\mathrm{H} 9 \mathrm{C} 2$. Uptake of $\mathrm{DioC}_{18}$ (3)-labelled exosomes by $\mathrm{H} 9 \mathrm{C} 2$ in vitro (magnification, $\mathrm{x} 400$ ). $\mathrm{H} 9 \mathrm{C} 2$ cells incorporated $\mathrm{DioC}_{18}(3)$-labelled exosomes from CPCs following incubation for $12 \mathrm{~h}$. Green dots indicate CPC-derived exosomes incorporated in $\mathrm{H} 9 \mathrm{C} 2$ cells. CPCs, cardiac progenitor cells.
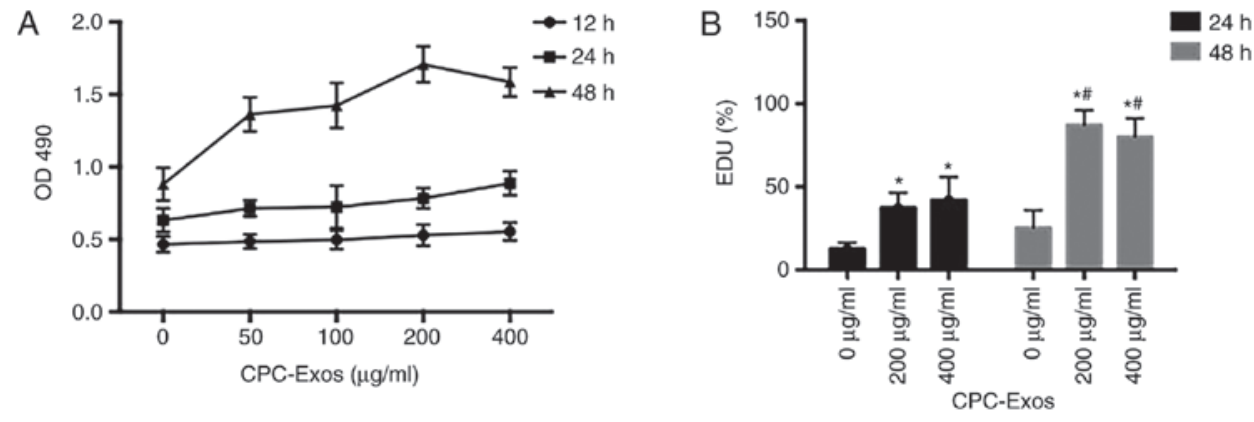

Figure 3. CPC-derived exosomes promote $\mathrm{H} 9 \mathrm{C} 2$ cell growth in a time- and concentration-dependent manner. $\mathrm{H} 9 \mathrm{C} 2$ cells were treated with $\mathrm{CPC}$-exosomes at 0 , $50,100,200$ and $400 \mu \mathrm{g} / \mathrm{ml}$ respectively. (A) Following incubation for 12,24 and $48 \mathrm{~h}$, cell growth was examined using a methyl-thiazolyl-tetrazolium assay. At the same concentration, cell growth in the $48 \mathrm{~h}$ group was higher than that in the $24 \mathrm{~h}$ group, which was higher than that in the $12 \mathrm{~h}$ group, and the differences were statistically significant $(\mathrm{P}<0.05)$. At the same treatment duration of $48 \mathrm{~h}$, cell growth with $200 \mu \mathrm{g} / \mathrm{ml} \mathrm{CPC}$-derived exosomes was higher than that in the other groups $(\mathrm{P}<0.05)$, and each group at $48 \mathrm{~h}$ was significantly different compared with the control $(0 \mu \mathrm{g} / \mathrm{ml})(\mathrm{P}<0.05)$. In the $24 \mathrm{~h}$ group, activation of cell growth with $400 \mu \mathrm{g} / \mathrm{ml}$ of exosome was significantly higher $(\mathrm{P}<0.05)$, compared with that in the control $(0 \mu \mathrm{g} / \mathrm{ml})$. Following treatment with CPC-exosomes for 24 and $48 \mathrm{~h}$ with the different final concentration of 0,200 and $400 \mu \mathrm{g} / \mathrm{ml}$, cell proliferation was determined using the EdU method. (B) Compared with the control $(0 \mu \mathrm{g} / \mathrm{ml})$, stimulation of cell proliferation in the 200 and $400 \mu \mathrm{g} / \mathrm{ml}$ groups differed significantly ( $\mathrm{P}<0.05$, vs. control). At the same concentration, activation in the $48 \mathrm{~h}$ groups differed significantly $\left({ }^{*} \mathrm{P}<0.05\right)$. CPC, cardiac progenitor cells; Exos, exosomes; OD, optical density; EdU, 5-ethynyl-2'-deoxyuridine.

corresponding to an increase in treatment time. The protein expression and phosphorylation of mTOR were activated by exosomes, however, the results were not the same as those for mRNA. In the $200 \mu \mathrm{g} / \mathrm{ml}$ group, the protein expression and phosphorylation were increased in correspondence with an increase in time, however, the opposite was true for protein expression in the $400 \mu \mathrm{g} / \mathrm{ml}$ group. At the different concentrations, the expression levels were higher in the $200 \mu \mathrm{g} / \mathrm{ml}$ groups than in the $400 \mu \mathrm{g} / \mathrm{ml}$ groups at $48 \mathrm{~h}$ (Fig. 5A-C).

\section{Discussion}

Cardiovascular disease remains a major contributor to rates of morbidity and mortality worldwide. CPCs derived from adult hearts appear to be a promising type of stem cell for myocardial regeneration and repair. This assumption is based on the hypothesis that CPCs can engraft, differentiate and replace damaged cardiac tissues. Increasing evidence has revealed the therapeutic benefits of CPC paracrine secretion (19). Following transplantation into an injured heart, CPCs can contribute to myocardial repair through direct and indirect mechanisms, including direct transdifferentiation into CMs and vascular cells, secretion of paracrine factors that may regulate the hyperplasia proliferation of existing CMs, and cell fusion between transplanted cells and existing CMs (20). Furthermore, numerous studies have shown that transplanted
CPCs can secrete a number of functional factors to reduce tissue injury and/or enhance tissue repair $(2,11)$.

Exosomes are small membrane vesicles that are actively released by cells in physiological and pathological states $(6,7)$. Exosomes contain various molecular constituents of RNA and soluble proteins and may be involved in cell-to-cell signalling. Exosomes deliver a cargo of RNA molecules, including mRNA and miRNAs, which have multiple biological effects and regulate gene expression within recipient cells (8). It is widely recognised that exosomes can mediate between paracrine signals within the cardiovascular system, for example, between endothelial cells and vascular smooth muscle cells (VSMCs) (21), between cardiac fibroblasts and CMs (22), and between VSMCs (23). Exosomes from the cardiovascular system also exist in pericardial fluid (24) and in the circulation (25), revealing their potential role in endocrine signalling.

In the present study, CPC-derived exosomes were extracted to investigate whether they can affect $\mathrm{H} 9 \mathrm{C} 2$ cell growth to examine the associated signalling pathways. The results demonstrated that the CPC-derived exosomes promoted H9C2 cell growth in a time- and concentration-dependent manner. The H9C2 cells exhibited an increased growth capacity following treatment with a higher concentration of CPC-derived exosomes or a longer acting time. Zhang et al reported that exosomes derived from $\mathrm{H} 9 \mathrm{C} 2$ cells carry certain 

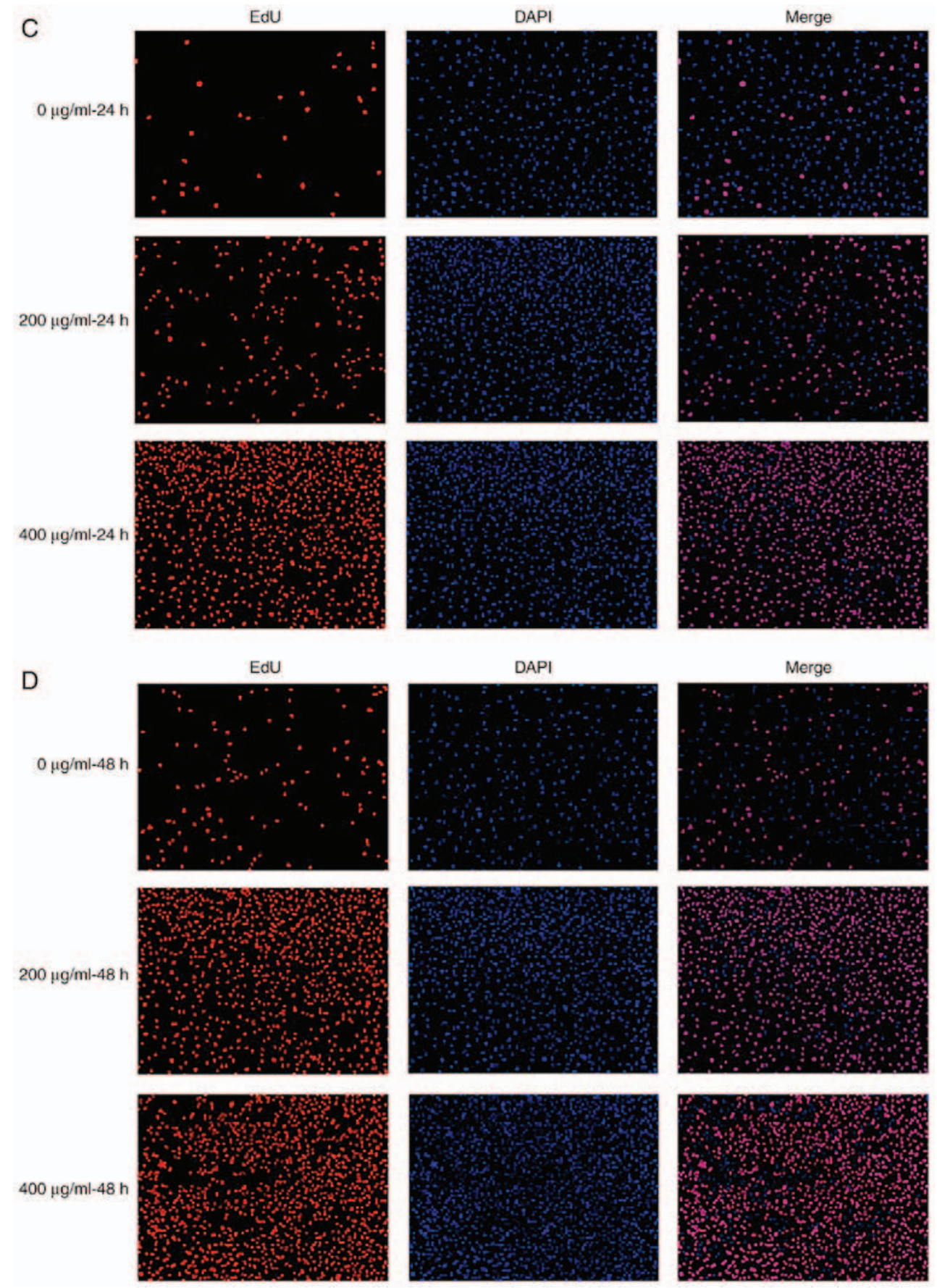

Figure 3. Continued. CPC-derived exosomes promote $\mathrm{H} 9 \mathrm{C} 2$ cell growth in a time- and concentration-dependent manner. Cell proliferation in the (C) $24 \mathrm{~h}$ and (D) $48 \mathrm{~h}$ groups was observed using fluorescence microscope following staining (magnification, $\mathrm{x} 100$ ). When treated with the same cardiac progenitor cell-derived exosomes, cell proliferation was simulated as treatment time increased. EdU, 5-ethynyl-2'-deoxyuridine.

cardioprotective miRNAs, which repress hypoxia-induced apoptosis. Among the hypoxia-induced exosomal miRNAs, miR-152-3p and let-7i-5p exert an anti-apoptotic function by targeting autophagy related 12 and Fas ligand, respectively (26). Cui et al confirmed that adipose-derived mesenchymal stem cell exosomes protect the ischemic myocardium from ischemia/reperfusion injury via activation of the Wnt/ $\beta$-catenin signal pathway (27). Shao et al found that MSC-derived exosomes (MSC-Exo) inhibit cardiac fibrosis and inflammation, and improve cardiac function. The MSC-Exo facilitated the proliferation of $\mathrm{H} 9 \mathrm{C} 2$ cells, suppressed apoptosis induced by $\mathrm{H}_{2} \mathrm{O}_{2}$ and inhibited the transformation of fibroblast cells into myofibroblasts induced by transforming growth factor- $\beta$ (28). Xiao et al revealed that CPC-derived exosomal miR-21 had an inhibitory function in the apoptotic process by downregulating the expression of programmed cell death 4 (PDCD4). Therefore, CPC-derived exosomes protected CMs against oxidative stress-related apoptosis by restoring the miR-21/PDCD4 pathway (29).

In the present study, it was found that CPC-derived exosomes stimulated the expression and phosphorylation of Akt, with the treatment concentration and time demonstrating an effect. Furthermore, CPC-derived exosomes facilitated the expression and phosphorylation of mTOR at a relatively low 

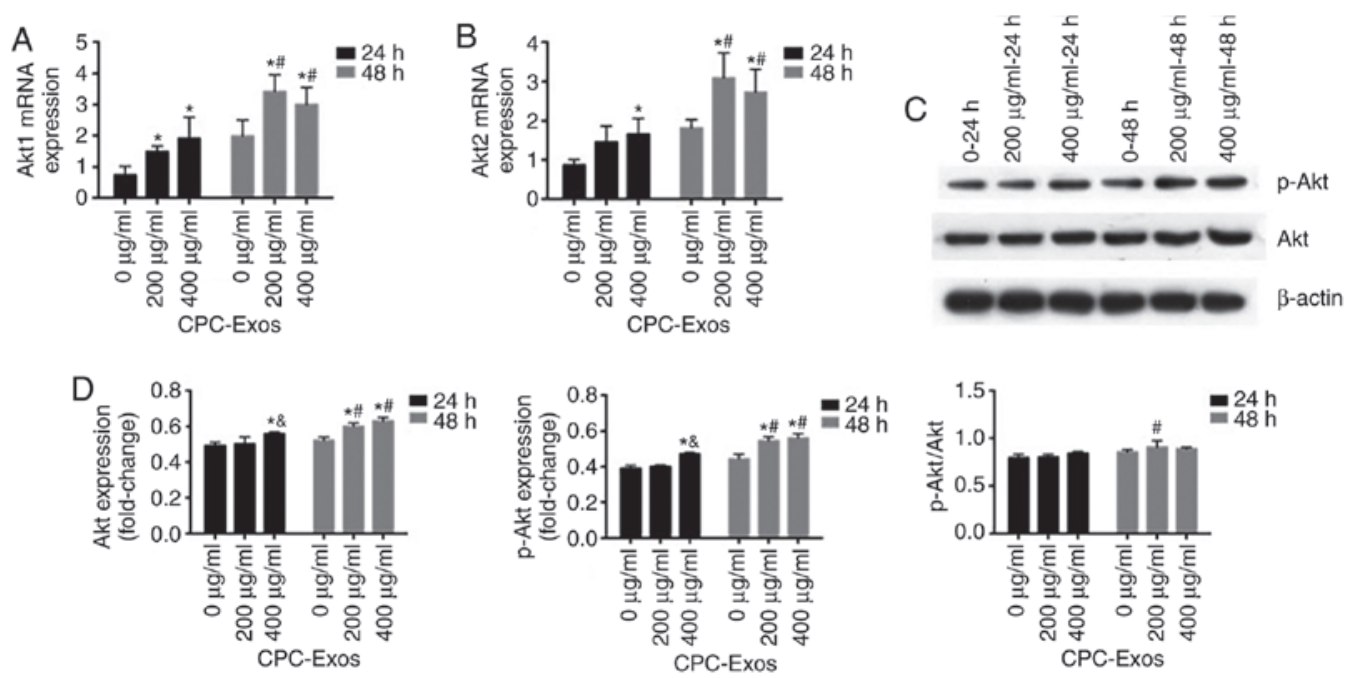

Figure 4. CPC-derived exosomes stimulate the expression of Akt and its phosphorylation. H9C2 cells were treated with CPC-exosomes with final concentrations of 0,200 and $400 \mu \mathrm{g} / \mathrm{ml}$. Cell lysates were harvested at 24 and $48 \mathrm{~h}$, and expression of Akt was determined by RT-qPCR and western blot analyses. mRNA expression levels of (A) Akt1 and (B) Akt2 were determined by RT-qPCR analysis (mean \pm standard error of the mean, $\mathrm{n}=3$ ) and normalized to the internal control $\beta$-actin, which was arbitrarily set to a value of 1.0. Compared with the control $(0 \mu \mathrm{g} / \mathrm{ml})$, expression levels of Akt1 and Akt2 in the 200 and $400 \mu \mathrm{g} / \mathrm{ml}$ groups were significantly higher ( $\mathrm{P}<0.05)$. At the same concentration, expression levels of Akt1 and Akt2 in the $48 \mathrm{~h}$ groups were significantly higher than those in the $24 \mathrm{~h}$ group $\left({ }^{\#} \mathrm{P}<0.05\right)$. (C) Samples were immunoblotted with $\beta$-actin to ensure equal protein loading and (D) results are shown in graphs (mean \pm standard error of the mean, $\mathrm{n}=3$ ). Compared with the control $(0 \mu \mathrm{g} / \mathrm{ml})$, expression levels of Akt and $\mathrm{p}-\mathrm{Akt}$ in the $200 \mu \mathrm{g} / \mathrm{ml} 48 \mathrm{~h}$ group, $400 \mu \mathrm{g} / \mathrm{ml} 24$ group and $400 \mu \mathrm{g} / \mathrm{ml} 48 \mathrm{~h}$ group were significantly higher ( $\mathrm{P}<0.05)$. Compared with the $200 \mu \mathrm{g} / \mathrm{ml}$ group, activation of Akt and p-Akt in the $24 \mathrm{~h}$ group was significantly higher in the $400 \mu \mathrm{g} / \mathrm{ml}$ group $\left({ }^{\circledR} \mathrm{P}<0.05\right)$. At the same concentration, the expression of Akt and p-Akt in the $48 \mathrm{~h}$ group, and the ratio of p-Akt/Akt in the $48 \mathrm{~h}$ group were significantly different $\left({ }^{*} \mathrm{P}<0.05\right)$. p-, phosphorylated; RT-qPCR, reverse transcription-quantitative polymerase chain reaction; CPC, cardiac progenitor cells; Exos, exosomes.
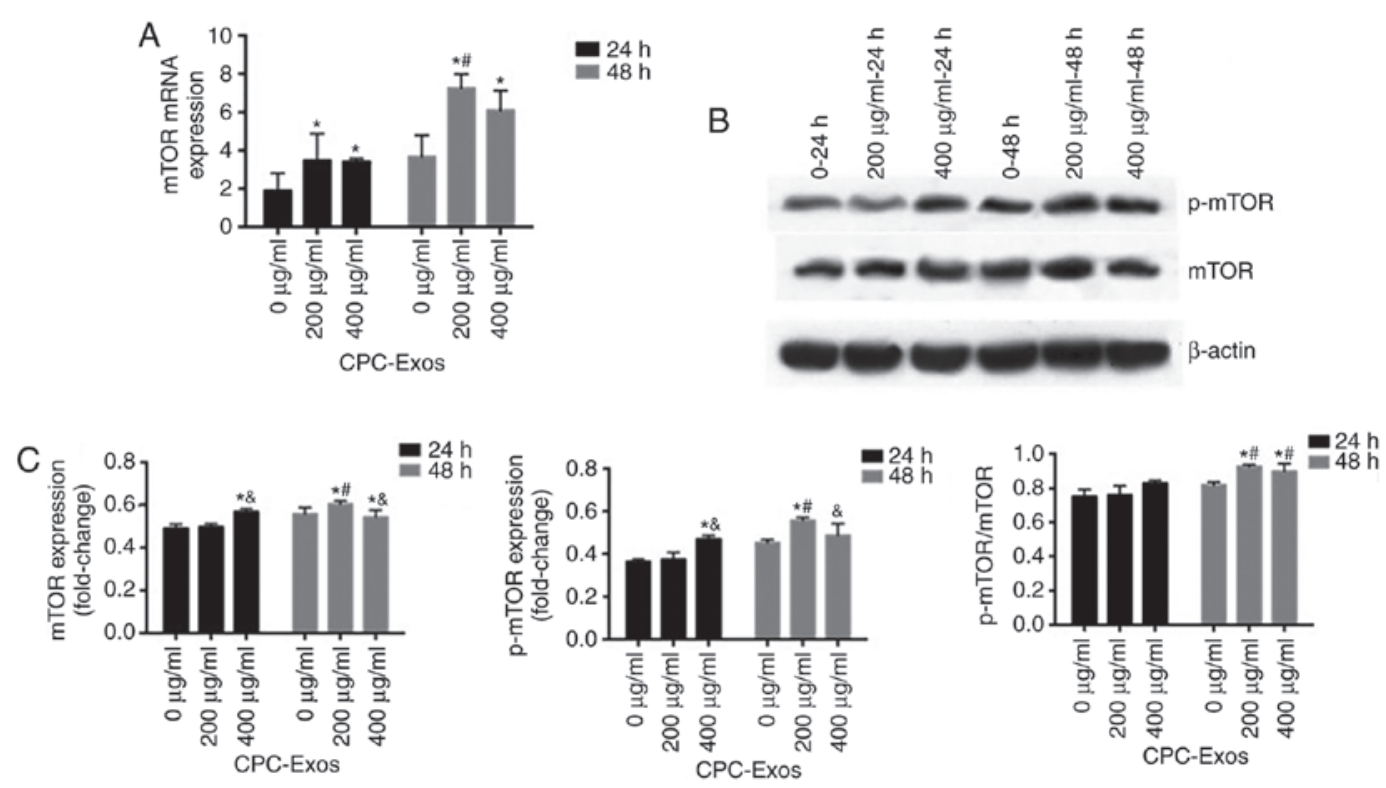

Figure 5. CPC-derived exosomes stimulate the expression of mTOR and its phosphorylation in a relatively low exosome concentration. H9C2 cells were treated with CPC-exosomes with final concentrations of 0,200 and $400 \mu \mathrm{g} / \mathrm{ml}$. Cell lysates were harvested at 24 and $48 \mathrm{~h}$, and the expression of mTOR was determined by RT-qPCR and western blot analyses. (A) mRNA expression levels were determined by RT-qPCR analysis (mean \pm standard error of the mean, $\mathrm{n}=3$ ) and normalized to the internal control $\beta$-actin, which was arbitrarily set to a value of 1.0 . Compared with the control $(0 \mu \mathrm{g} / \mathrm{ml})$, expression levels of mTOR in the 200 and $400 \mu \mathrm{g} / \mathrm{ml}$ groups were significantly higher ( ${ }^{*} \mathrm{P}<0.05$ ). (B) Samples were immunoblotted with an antibody to $\beta$-actin to ensure equal protein loading and (C) results are shown in graphs (mean \pm standard error of the mean, $\mathrm{n}=3$ ). Compared with the control $(0 \mu \mathrm{g} / \mathrm{ml})$, expression levels of mTOR and p-mTOR in the $200 \mu \mathrm{g} / \mathrm{ml} 48 \mathrm{~h}$ group and $400 \mu \mathrm{g} / \mathrm{ml}$ group 24 and $48 \mathrm{~h}$, and the ratio of p-mTOR/mTOR at $48 \mathrm{~h}$ were significantly higher ("P $<0.05)$. Compared with the $200 \mu \mathrm{g} / \mathrm{ml} 24$ and $48 \mathrm{~h}$ groups, the expression levels of mTOR and p-mTOR in the $400 \mu \mathrm{g} / \mathrm{ml}$ group were significantly different ( $\left.{ }^{\circledR} \mathrm{P}<0.05\right)$. At the same concentration at different times, the expression levels of mTOR and p-mTOR and ratio of p-mTOR/mTOR were significantly higher $\left({ }^{\#} \mathrm{P}<0.05\right)$. $\mathrm{mTOR}$, mammalian target of rapamycin; p-, phosphorylated; RT-qPCR, reverse transcription-quantitative polymerase chain reaction; CPC, cardiac progenitor cells; Exos, exosomes.

exosome concentration $(200 \mu \mathrm{g} / \mathrm{ml})$. Therefore, the results showed that CPC-derived exosomes may promote $\mathrm{H} 9 \mathrm{C} 2$ cell growth via the activation of $\mathrm{Akt} / \mathrm{mTOR}$ in a relatively time- and concentration-dependent manner. 
The PI3K/AKT/mTOR intracellular signalling pathway is important in regulating the cell cycle and is essential to promote the growth, proliferation and differentiation of adult stem cells, specifically (30). The activation of Akt has vital effects on the CMs, including increasing cell size, inhibiting apoptosis and altering glucose metabolism (31). In addition, several studies have revealed that the PI3K/Akt/mTOR signalling pathway may contribute to cardioprotection, although the mechanisms remain to be fully elucidated. Li et al found that tanshinone IIA activated the PI3K/Akt/mTOR signalling pathway and protected against myocardial ischemia reperfusion injury (32). Another finding suggested that nerve growth factor exerts a cardioprotective effect by a variety of mechanisms that restore autophagic flux and the attenuation of protein ubiquitination through activation of the PI3K/AKT/mTOR pathway (33). Zhang et al provided evidence that sevoflurane-induced postconditioning, as a mechanism of cardioprotection, was mediated by activation of the PI3K/AKT/mTOR pathway, which included an anti-apoptotic effect on CMs and the protection of mitochondria from injury (34). Wang et al found that basic fibroblast growth factor had an effect on myocardial cell death in vivo and in vitro and required activation of the PI3K/Akt/mTOR signalling pathway (35).

A previous investigation indicated that jujuboside A has a potential protective effect on isoproterenol (ISO)-induced damage in $\mathrm{H} 9 \mathrm{C} 2$ cells by accelerating activation of the PI3K/Akt/mTOR signalling pathway (36). The $\mathrm{PI} 3 \mathrm{~K} / \mathrm{Akt} / \mathrm{mTOR}$ pathway is also involved in promoting autophagy in $\mathrm{H} 9 \mathrm{C} 2$ cells induced by low-after-high glucose (37). In addition, two studies have revealed that the $\mathrm{PI} 3 \mathrm{~K} / \mathrm{Akt} / \mathrm{mTOR}$ signalling pathway is involved in cardioprotection by inhibiting CM apoptosis and autophagy. Radix Paeoniae Rubra terpene glycosides may protect the heart from ISO-induced myocardial ischemia by improving cardiac energy metabolism and inhibiting CM apoptosis via activation of the PI3K/AKT/mTOR signalling pathway (38). Apigenin may have a protective effect against adriamycin-induced cardiotoxicity by inhibiting apoptosis and autophagy via activation of the PI3K/AKT/mTOR pathway (39). A previous study in mice suggested that macrophage migration inhibitory factor facilitated the survival of mouse cardiac stem cells, and the proliferation and differentiation of endothelial cells via activation of the $\mathrm{PI} 3 \mathrm{~K} / \mathrm{Akt} / \mathrm{mTOR}$ signalling pathway (40). These studies demonstrate that the PI3K/AKT/mTOR pathway has an important regulatory function in cardioprotection.

The results of the present study provide a novel approach for investigating the role of CPCs and cardiosphere-derived cells in heart disease research. CPCs are a compounded group of cells distributed throughout cardiac tissue that can be activated and can differentiate into new muscle or vascular cells following stress or injury (20). The present study provided evidence that CPC-derived exosomes promoted $\mathrm{H} 9 \mathrm{C} 2$ cell growth. However, further investigations are required to determine the exact mechanism underlying the effect of CPC-derived exosomes in cardioprotection, including the role of specific miRNAs transferred in exosomes, the regulation effect of CPC-derived exosomes on energy metabolism, and the apoptosis and autophagy of CMs.

\section{Acknowledgements}

The authors would like to thank the Center Laboratory at The Third Xiangya Hospital of Central South University for the provision of experimental equipment and technical guidance necessary to complete the work.

\section{Funding}

This study was funded by the National Natural Science Foundation (grant no. 81500225).

\section{Availability of data and materials}

The datasets used and analyzed during the current study are available from the corresponding author on reasonable request.

\section{Authors' contributions}

XL conceived and designed the experiments. SL conducted the experiments. JJ, ZY and ZL participated in the completion of the experiments. SL and XM analyzed the data. SL wrote the paper. XL revised the manuscript. All the authors read and approved the final paper.

\section{Ethics approval and consent to participate}

All experiments were conducted in accordance with the IRB of The Third Xiangya Hospital, Central South University (Changsha, China; no. 2015-S001).

\section{Patient consent for publication}

Not applicable.

\section{Competing interests}

The authors declare that they have no competing interests.

\section{References}

1. Yu B, Kim HW, Gong M, Wang J, Millard RW, Wang Y, Ashraf M and $\mathrm{Xu} \mathrm{M}$ : Exosomes secreted from GATA-4 overexpressing mesenchymal stem cells serve as a reservoir of anti-apoptotic microRNAs for cardioprotection. Int J Cardiol 182: 349-360, 2015.

2. Barile L, Lionetti V, Cervio E, Matteucci M, Gherghiceanu M, Popescu LM, Torre T, Siclari F, Moccetti T and Vassalli G: Extracellular vesicles from human cardiac progenitor cells inhibit cardiomyocyte apoptosis and improve cardiac function after myocardial infarction. Cardiovasc Res 103: 530-541, 2014.

3. Sluijter JP, Verhage V, Deddens JC, van den Akker F and Doevendans PA: Microvesicles and exosomes for intracardiac communication. Cardiovasc Res 102: 302-311, 2014.

4. Waqas MY,Zhang Q, Ahmed N, Yang P, Xing G, Akhtar M, Basit A, Liu T, Hong C, Arshad M, et al: Cellular evidence of exosomes in the reproductive tract of Chinese soft-shelled turtle pelodiscus sinensis. J Exp Zool A Ecol Genet Physiol 327: 18-27, 2017.

5. Ailawadi S, Wang X, Gu H and Fan GC: Pathologic function and therapeutic potential of exosomes in cardiovascular disease. Biochim Biophys Acta 1852: 1-11, 2015.

6. Kharaziha P,Ceder S, Li Q and Panaretakis T: Tumor cell-derived exosomes: A message in a bottle. Biochim Biophys Acta 1826: 103-111, 2012.

7. Kalani A, Tyagi A and Tyagi N: Exosomes: Mediators of neurodegeneration, neuroprotection and therapeutics. Mol Neurobiol 49: 590-600, 2014. 
8. Jiang XC and Gao JQ: Exosomes as novel bio-carriers for gene and drug delivery. Int J Pharm 521: 167-175, 2017.

9. Wu L, Zhang X, Zhang B, Shi H, Yuan X, Sun Y, Pan Z, Qian H and $\mathrm{Xu} \mathrm{W}$ : Exosomes derived from gastric cancer cells activate $\mathrm{NF}-\kappa \mathrm{B}$ pathway in macrophages to promote cancer progression. Tumour Biol 37: 12169-12180, 2016.

10. Zhao B, Zhang Y, Han S, Zhang W, Zhou Q, Guan H, Liu J, Shi J, $\mathrm{Su} \mathrm{L}$ and $\mathrm{Hu} \mathrm{D}$ : Exosomes derived from human amniotic epithelial cells accelerate wound healing and inhibit scar formation. J Mol Histol 48: 121-132, 2017.

11. Chen L, Wang Y, Pan Y, Zhang L, Shen C, Qin G, Ashraf M, Weintraub N, Ma G and Tang Y: Cardiac progenitor-derived exosomes protect ischemic myocardium from acute ischemia/reperfusion injury. Biochem Biophys Res Commun 431: 566-571, 2013

12. Virtakoivu R, Pellinen T, Rantala JK, Perälä M and Ivaska J: Distinct roles of AKT isoforms in regulating $\beta 1$-integrin activity, migration, and invasion in prostate cancer. Mol Biol Cell 23 3357-3369, 2012

13. Qu JL, Qu XJ, Zhao MF, Teng YE, Zhang Y, Hou KZ, Jiang YH, Yang XH and Liu YP: Gastric cancer exosomes promote tumour cell proliferation through PI3K/Akt and MAPK/ERK activation. Dig Liver Dis 41: 875-880, 2009.

14. Malik ZA, Kott KS, Poe AJ, Kuo T, Chen L, Ferrara KW and Knowlton AA: Cardiac myocyte exosomes: Stability, HSP60, and proteomics. Am J Physiol Heart Circ Physiol 304: H954-H965, 2013.

15. Hinescu ME, Gherghiceanu M, Suciu L and Popescu LM: Telocytes in pleura: Two- and three-dimensional imaging by transmission electron microscopy. Cell Tissue Res 343: 389-397, 2011.

16. Livak KJ and Schmittgen TD: Analysis of relative gene expression data using real-time quantitative PCR and the 2(-Delta Delta C(T)) method. Methods 25: 402-408, 2001.

17. Zhang Y, Zheng Y, Faheem A, Sun T, Li C, Li Z, Zhao D, Wu C and Liu J: A novel AKT inhibitor, AZD5363, inhibits phosphorylation of AKT downstream molecules, and activates phosphorylation of mTOR and SMG-1 dependent on the liver cancer cell type. Oncol Lett 11: 1685-1692, 2016.

18. Hasson SP, Rubinek T, Ryvo L and Wolf I: Endocrine resistance in breast cancer: Focus on the phosphatidylinositol 3-kinase/akt/mammalian target of rapamycin signaling pathway. Breast Care (Basel) 8: 248-255, 2013.

19. Chimenti I, Smith RR, Li TS, Gerstenblith G, Messina E, Giacomello A and Marbán E: Relative roles of direct regeneration versus paracrine effects of human cardiosphere-derived cells transplanted into infarcted mice. Circ Res 106: 971-980, 2010.

20. Le T and Chong J: Cardiac progenitor cells for heart repair. Cell Death Discov 2: 16052, 2016

21. Hergenreider E, Heydt S, Tréguer K, Boettger T, Horrevoets AJ, Zeiher AM, Scheffer MP, Frangakis AS, Yin X, Mayr M, et al: Atheroprotective communication between endothelial cells and smooth muscle cells through miRNAs. Nat Cell Biol 14: 249-256, 2012

22. Bang C, Batkai S, Dangwal S, Gupta SK, Foinquinos A, Holzmann A, Just A, Remke J, Zimmer K, Zeug A, et al: Cardiac fibroblast-derived microRNA passenger strand-enriched exosomes mediate cardiomyocyte hypertrophy. J Clin Invest 124 : 2136-2146, 2014

23. Kapustin AN, Chatrou ML, Drozdov I, Zheng Y, Davidson SM, Soong D, Furmanik M, Sanchis P, De Rosales RT, Alvarez-Hernandez D, et al: Vascular smooth muscle cell calcification is mediated by regulated exosome secretion. Circ Res 116: $1312-1323,2015$

24. Beltrami C, Besnier M, Shantikumar S, Shearn AI, Rajakaruna C, Laftah A, Sessa F, Spinetti G, Petretto E, Angelini GD and Emanueli C: Human pericardial fluid contains exosomes enriched with cardiovascular-expressed MicroRNAs and promotes therapeutic angiogenesis. Mol Ther 25: 679-693, 2017.

25. Pironti G, Strachan RT, Abraham D, Mon-Wei Yu S, Chen M, Chen W, Hanada K, Mao L, Watson LJ and Rockman HA: Circulating exosomes induced by cardiac pressure overload contain functional angiotensin II type 1 receptors. Circulation 131: 2120-2130, 2015.
26. Zhang J, Ma J, Long K, Qiu W, Wang Y, Hu Z, Liu C, Luo Y, Jiang A, Jin L, et al: Overexpression of exosomal cardioprotective miRNAs mitigates hypoxia-induced H9c2 cells apoptosis. Int J Mol Sci 18: E711, 2017.

27. Cui X, He Z, Liang Z, Chen Z, Wang H and Zhang J: Exosomes from adipose-derived mesenchymal stem cells protect ischemic myocardium from ischemia/reperfusion injury via Wnt/ $\beta$-catenin signaling pathway. J Cardiovasc Pharmacol 70: 225-231, 2017.

28. Shao L, Zhang Y, Lan B, Wang J, Zhang Z, Zhang L, Xiao P, Meng Q, Geng YJ, Yu XY and Li Y: MiRNA-sequence indicates that mesenchymal stem cells and exosomes have similar mechanism to enhance cardiac repair. Biomed Res Int 2017: 4150705, 2017.

29. Xiao J, Pan Y, Li XH, Yang XY, Feng YL, Tan HH, Jiang L, Feng J and Yu XY: Cardiac progenitor cell-derived exosomes prevent cardiomyocytes apoptosis through exosomal miR-21 by targeting PDCD4. Cell Death Dis 7: e2277, 2016.

30. Peltier J, O'Neill A and Schaffer DV: PI3K/Akt and CREB regulate adult neural hippocampal progenitor proliferation and differentiation. Dev Neurobiol 67: 1348-1361, 2007.

31. Latronico MV, Costinean S, Lavitrano ML, Peschle C and Condorelli G: Regulation of cell size and contractile function by AKT in cardiomyocytes. Ann N Y Acad Sci 1015: 250-260, 2004.

32. Li Q, Shen L, Wang Z, Jiang HP and Liu LX: Tanshinone IIA protects against myocardial ischemia reperfusion injury by activating the PI3K/Akt/mTOR signaling pathway. Biomed Pharmacother 84: 106-114, 2016.

33. Campenot RB: Local control of neurite development by nerve growth factor. Proc Natl Acad Sci USA 74: 4516-4519, 1977.

34. Zhang J, Wang C, Yu S, Luo Z, Chen Y, Liu Q, Hua F, Xu G and Yu P: Sevoflurane postconditioning protects rat hearts against ischemia-reperfusion injury via the activation of PI3K/AKT/mTOR signaling. Sci Rep 4: 7317, 2014.

35. Wang ZG, Wang Y, Huang Y, Lu Q, Zheng L, Hu D, Feng WK, Liu YL, Ji KT, Zhang HY, et al: bFGF regulates autophagy and ubiquitinated protein accumulation induced by myocardial ischemia/reperfusion via the activation of the PI3K/Akt/mTOR pathway. Sci Rep 5: 9287, 2015.

36. Han D, Wan C, Liu F, Xu X, Jiang L and Xu J: Jujuboside a protects $\mathrm{H} 9 \mathrm{C} 2$ cells from isoproterenol-induced injury via activating PI3K/Akt/mTOR signaling pathway. Evid Based Complement Alternat Med 2016: 9593716, 2016.

37. Leithe $\mathrm{E}$ and Rivedal E: Ubiquitination and down-regulation of gap junction protein connexin-43 in response to 12-O-tetradecanoylphorbol 13-acetate treatment. J Biol Chem 279: 50089-50096, 2004.

38. Ke Z, Wang G, Yang L, Qiu H, Wu H, Du M, Chen J, Song J, Jia X and Feng L: Crude terpene glycoside component from Radix paeoniae rubra protects against isoproterenol-induced myocardial ischemic injury via activation of the PI3K/AKT/mTOR signaling pathway. J Ethnopharmacol 206: 160-169, 2017.

39. Yu W, Sun H, Zha W, Cui W, Xu L, Min Q and Wu J: Apigenin attenuates adriamycin-induced cardiomyocyte apoptosis via the PI3K/AKT/mTOR pathway. Evid Based Complement Alternat Med 2017: 2590676, 2017.

40. Cui J, Zhang F, Wang Y, Liu J, Ming X, Hou J, Lv B, Fang S and Yu B: Macrophage migration inhibitory factor promotes cardiac stem cell proliferation and endothelial differentiation through the activation of the PI3K/Akt/mTOR and AMPK pathways. Int J Mol Med 37: 1299-1309, 2016.

This work is licensed under a Creative Commons Attribution-NonCommercial-NoDerivatives 4.0 International (CC BY-NC-ND 4.0) License. 